\title{
URSS-USA: Las artes de sus ideales en la fotografía
}

\author{
juan Pando Despierto *
}

\section{UN IDEAL DE INCORPORACION Y OTRO DE PROCLAMACIÓN}

La desarticulación de la Unión Soviética en agosto-septiembre de 1991, rompe el gran debate gráfico que dos sistemas, dos ideologías y dos sociedades, habian mantenido desde el momento mismo en que ambas voluntades quedaron como las «únicas posibles" luego de la gran convulsión de 1939-45. Sería extremadamente simple sintetizar la formidable pugna como un debate entre comunismo y capitalismo. En realidad, se trataba de dos estrategias más que de dos revoluciones, con sus estéticas y deontologias respectivas, con lo que los ideales, al final, se encontraban seriamente amenazados en el núcleo mismo donde se formaban. Ahora sólo permanece en pie una de estas fuerzas, pero en modo alguno puede considerarse ésta el ideal triunfante, sino tan sólo el ideal subsistente, es decir, el que todavía no se ha formado.

Los Estados Unidos de América son ejemplo de un ideal de incorporación, por la llegada a su seno del masivo pero benéfico oleaje migratorio mundial en el alborear del conocimiento vigésimo de nuestra civilización. Sólo entre 1900 y 1914, más de 13 millones de inmigrantes llegaron a lo que comenzaba a ser ya el "sueño americano". El 91,52\% de ellos eran europeos ${ }^{1}$. El viejo continente, por primera vez, no efectua-

* Departamento de Historia del Arte. UNED.

' KASPI, André, Les Américains. Les Etats Unis de 1607 à nos jours, 697 págs. Paris, Editions du Seuil, 1986, pág. 244. 
ba una más de sus acciones colonizadoras tradicionales. El proceso era a la inversa: desencantados de los viejos regímenes, de las viejas conductas estamentales, los europeos llegaban a los espacios americanos dispuestos a "recibir" el ideal, cuando ellos, en sí mismos, eran el ideal, muy distinto del calvinismo elemental transportado por el Mayflower en 1620.

En Europa, la libertad era sólo un acto intelectual (como siempre). Las miserias del proletariado en Gran Bretaña, paradigma de las democracias, testificaban de ello. Entonces Europa "se echó al mar", y esta potencia inmensa, física y espiritual, es la que conformó el ideal norteamericano: el multinacionalismo, la internacionalización del respeto a los demás, el verdadero ideal. Si democracia es multipartidismo y gobierno del pueblo, los Estados Unidos, al recibir la "suma de la historia" que llevaban en si las sociedades escandinava, latina, eslava y anglosajona (incluso china), que llegaban a sus costas en marea incesante, se elevaban no sólo como tierra de promisión, sino como certidumbre de que el ideal era únicamente posible si resultaba ser universal, como corresponde a todo ideal digno de ese nombre.

Por el contrario, Rusia, otra inmensidad histórica en expectativa de destino, vivía entonces inmersa en una acumulación de gestos medievales por parte de las instituciones. Baste decir que la ley electoral aprobada por el zar Nicolás II el 16 de junio de 1907 permitía a cada terrateniente elegir un representante por cada 230 electores, mientras que los campesinos necesitaban 60.000 electores para elegir a uno de los suyos. Los fracasos en dos guerras, ambas contra dos sistemas mundiales (el Mikado en 1904-05, y los imperios alemán y austro-húngaro en 19141917), llevaron a la detonación de todas las paciencias infinitas largamente sometidas. Ante la exposición de tanta barbarie, de tanta inconsciencia gubernamental y oligárquica, la revolución rusa no es que fuese una inevitabilidad, sino la concordancia de una desesperación interior con un movimiento de liberación exterior y mundial que representaba el marxismo. El pueblo ruso se liberó por sí y por los demás, de nuevo un ideal ecuménico. En diferencia al norteamericano, era un ideal no de incorporación, sino de proclamación. Pero el vigor de ambas potencias era virtualmente el mismo por su aseidad universalizante. 


\section{LAS PRIMERAS PRUEBAS}

Alfred Stieglitz (1864-1946), fotografió en 1907 la cubierta de un barco de emigrantes en su llegada a Nueva York. Aluvión de esperanzas, testimonio de orfandades eternizadas en las magnitudes frivolas de Europa. La multitud peregrina llega como masa sin nombre, dispuesta a recibir sus apellidos en un futuro agroindustrial (Fig. 1) en el que dicen "hay una oportunidad para todos".

En el otro reflejo, las calles de Petrogrado, la multitud huye despavorida mientras a sus espaldas suenan descargas cerradas. El pueblo es fusilado a mansalva, pero en realidad el que se está suicidando es el sistema. La gente corre y corre, luego se da cuenta que no hay escapatoria, que los límites han sido alcanzados y se revuelve. Es la Revolución de Octubre (noviembre según el calendario gregoriano). Viktor Bulla (1883-1944), hijo de fotógrafo, recogerá el estremecimiento de aquellos días que, literalmente, dieron "la vuelta al mundo", superando asi la concepción decimal de Jonh Reed.

Una fotografía de Bulla (Fig. 2), en 1920, realizada en la factoría Putílov de Petrogrado, bastión de la insumisión laboral contra el zarismo, muestra a una sociedad expectante, dotada de un vigor exponencial fuera de lo común. El zarismo es sólo un estremecimiento de osario, y el poder efectivamente es para los "soviets" (consejos) de obreros y soldados. La sociedad superviviente de la furia está orgullosa de sí misma, y las miradas que confluyen en el fotógrafo así lo atestiguan. Hay una inmensa confianza, una determinación sin duda "totalitaria»: la de cambiar el mundo, irrealidad donde los esfuerzos en el trabajo se tradujesen en idénticos beneficios para los luchadores del ideal, la derrota de las depravadas plusvalias del hombre contra el hombre.

La sociedad rusa dejó pronto de serlo y se convirtió en soviética. Algo imprescindible para poder acceder al ideal, pero que al confluir sobre viejos vicios (burocratismo, militarismo en las actitudes del Estado, emergencia de una partitocracia única), dinamitaría el ideal. Por su parte, los EEUU siguieron adelante. El ideal estribaba en hacerse más rico que el vecino, algo habitual en el hombre y que se habia contrastado desde el ágora ateniense al foro romano. En este contexto, Anton Breuhl (19001983), enfocó su cámara hacia una insólita línea de producción industrial: una cadena de rutilantes sombreros de copa, el distintivo ideal de la riqueza. Eran tantos y tan iguales que demostraban la validez revolucionaria norteamericana: todos ricos, luego todos seguros de sí mismos. ¿Tan rápidamente habian mejorado las multitudes penitentes de Stieglitz? 




Fig. 1 El entrepuente. New York 1907. Alfred Stieglitz. 




Fig. 2 Reunión del soviet de la fábrica Putilov en Petrogrado. 27 junio 1920. Viktor Bulla. 
Las administraciones de Harving y Coolidge extendieron la idea de que los Estados Unidos eran una «máquina de hacer felicidad». El mismo Coolidge, presidente que pasó a la historia con su lema keep cool with Coolidge ("Queda tranquilo con Coolidge»), decía que "el verdadero negocio de los EE.UU. eran los negocios" ${ }^{2}$. El hecho de que cada año brotaran cerca de diez mil nuevos millonarios parecía certificar concluyentemente tal aserto. Pero la fotografia de Breuhl (Fig. 3) está realizada en un año maldito: 1929, donde en tan sólo "dos días negros" (lunes 21 y jueves 24 de octubre), el espiritismo mercantilista del sucesor de Coolidge, Herbert $C$. Hoover, quedó convertido en un montón de papeles que el viento de la depresión esparció por todas las esquinas norteamericanas. Entonces, una tras otra, todas las chisteras cogieron impulso y saltaron por las ventanas de impávidos rascacielos. Algunas se salvaron.

\section{EL VALOR DE LA EXPERIENCIA: DE JAMES A ROOSEVELT}

Norteamérica es la tierra de la experiencia. Descubrir un semi-continente y construir una democracia eran sendos empeños geometafísicos con valor inhabitual. El ideal, enfrentado a estos desafíos colosales necesitaba hacerse "sensible», esto es, experimentado. Pierce, matemático renovador y honesto, había unificado to empírico (lo demostrable, la rutina), con lo algebraico (lo concordante, la creación). Pero William James, no matemático, despreció el valor de los números y efectuó una sorprendente coronación del «interés": "Lo verdadero es sólo lo ventajoso en nuestro modo de pensar, de igual forma que lo justo es sólo ventajoso en el modo de conducirnos" ${ }^{3}$. Estas razones, publicadas en 1909, causaron estragos, y aunque él mismo James contraatacó diciendo que «se habian malinterpretado", fueron los "salmos" de los políticos que sucedieron a Wilson, un idealista ejemplar obstinado en conseguir la paz universal desde el altar de la Sociedad de Naciones que sus famosos Catorce Puntos proclamaran.

Pero la catástrofe financiera de 1929 , sobrecarga de un ideal sometido a tensiones prostituyentes, hizo ver una nueva dimensión de la experiencia: la humildad. Franklin Delano Roosevelt recogió al país de entre

${ }^{2}$ Martinelli, Franco, Historia de los Estados Unidos, 2 volúmenes, tomo 1, 596 pág. Barcelona, Editorial De Vecchi, 1973, pág. 206.

3 JAMES, William, El significado de la verdad, traducción del inglés y prólogo de Luis Rodriguez Aranda. Buenos Aires, Editorial Aguilar Argentina, 1974, pág. 30. 


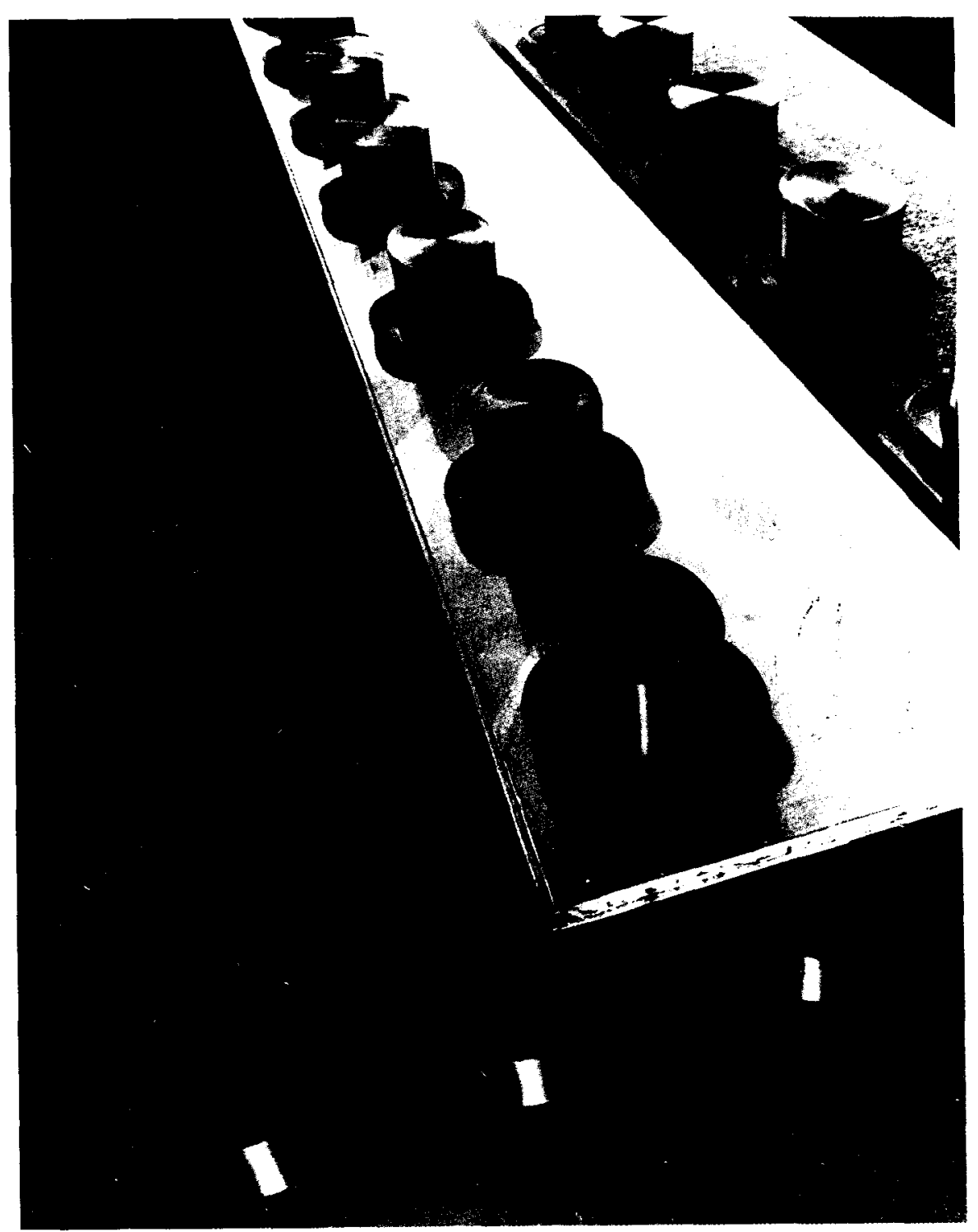

Fig. 3 Sombreros de copa. 1929. Anton Bruehl. 
las ruinas de su soberbia y le mostró el nuevo camino, que no era el New Deal, sino algo mucho más sencillo: reconocerse tal y como eran los norteamericanos. Para ello contó con nombres de la fortaleza psíquica y plástica de Walker Evans, Arthur Rothstein o Dorothea Lange. El país tenia que reinventar todo, desde una gestión eficaz en la administración del Estado, a nuevos conceptos en las relaciones humanas.

En esa primera mirada de Norteamérica sobre sí misma, hubo muchas sorpresas y bastantes esperanzas. Rhostein retrató en 1937 a una niña de color asomada a su ventana en Alabama: una gran inocencia, una constante soledad, una leve tristeza. La contraventana, en su «mirada" al interior, hablaba de consumismo y de éxitos holywoodenses. Al abrirse desde dentro, ese mundo periodístico descubría a la niña Aletia Berdolph la verdad informativa de su cotidianeidad: una vivienda construida con rollizos de madera e insterticios rellenos de barro y paja, moderno palafito de una eterna provisionalidad en las áreas suburbiales del sur confederal (Fig. 4).

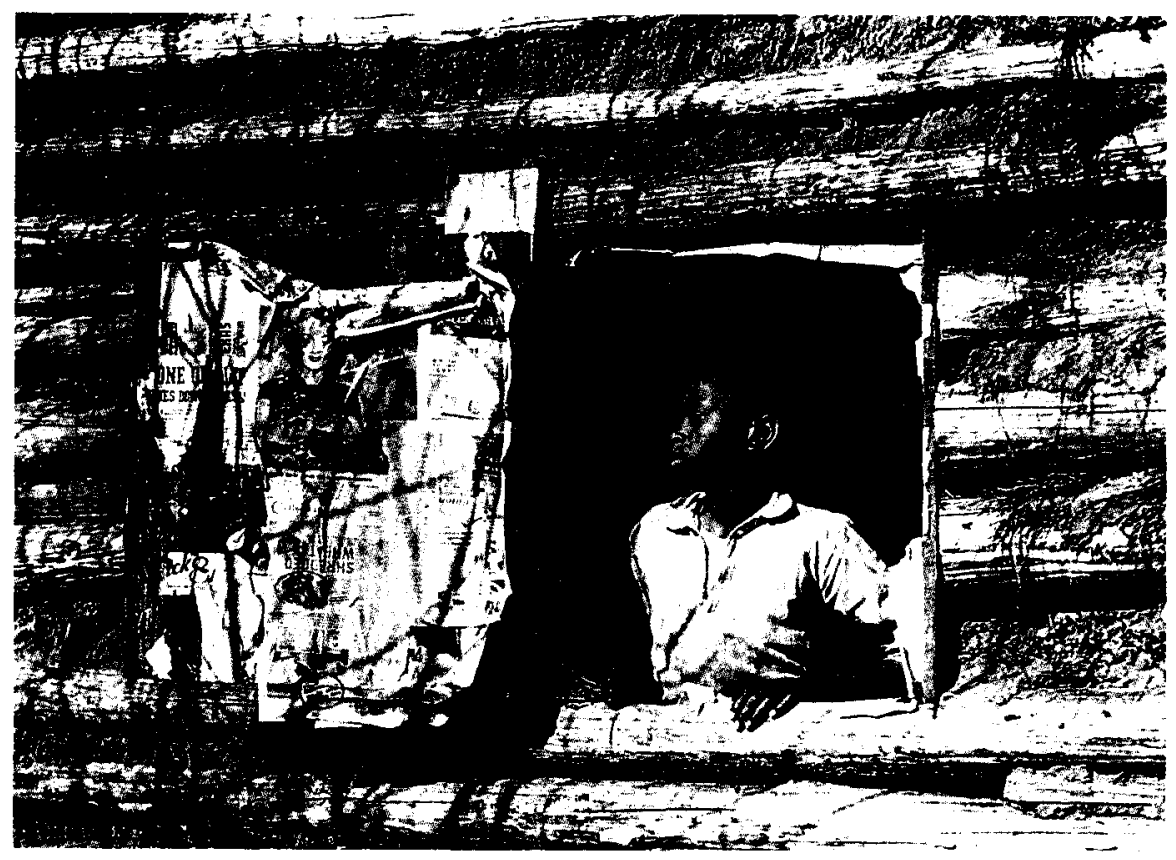

Fig. 4 Aletia Berdolph en su casa. Alabama 1937. Arthur Rothstein. 
La niña de Rothstein no puede saber que es compañera de generación de Martin Luther King (Atlanta, 1929), que demostrará a todo el país en los años kennedianos cómo es posible ser libre sin dejar de ser pragmático, esto es, norteamericano, y sin que la muerte brutal en un hotel de Memphis en 1968 interrumpiese una valiente meditación que millones de seres nacidos igualmente en el ideal seguirian tenazmente años después.

Se ha dicho que Norteamérica es tierra de grandes hombres (en realidad, todas las naciones y pueblos los tienen), pero sus mujeres resultarian excepcionales. Emily Dickinson, Isadora Duncan, Amelia Earhart - Margaret Mead, instituyeron modos de ser y de pensar decisivos en la poesía, la danza, la aviación o la antropología. Dorothea Lange (18951965) formaría parte, con todos los merecimientos, de ese peristilo femenino del templo de la creatividad estadounidense, caracterizado por su imaginación y sinceridad.



Fig. 5 Dueño de plantación. Misissipi. Dorothea Lange. 
Lange, trabajando según las directrices del subsecretario de Estado para la Agricultura en el gabinete de Roosevelt, Rexford Tugwell, formaría parte del equipo de fotógrafos reunido por Roy Stryker para documentar los logros de la FSA (Farm Security Administration), que trataba de auxiliar las voluntades rurales de los estados sureños y del Medio Oeste, entonces a la intemperie de toda productividad y coherencia. Uno de los originales de Lange, obtenido en 1936, en Missisipi, nos expone esa separación entre actitudes que sigue siendo una asiduidad histórica: los que mandan y los que obedecen. Pero Lange supo aportar el matiz diferenciador del "profundo sur" norteamericano: el que es dueño de todo y los que sólo son dueños de huir (si es que podian) (Fig. 5).

Walker Evans (1903-1975) era hombre que denunciaba el talante monetarista de su sociedad, incluso el de alguno de los dioses de la profesión, como Edward Steichen, amateur prestigiado que se había pasado, con armas y bagajes, al mundo de la publicidad, y donde ejercía en los años treinta como un auténtico "vudú» que extraía del manantial publicitario todo lo que el medio disponía y que era muchísimo. Christopher Philips, en la obra de conjunto sobre la historia de la Fotografía dirigida por Jean-Claude Lemagny y André Rouillé, recordaría esta cita de Evans: «La fotografía se ha equivocado de camino en este mundo de técnica arrogante y de no existencia espiritual» ${ }^{4}$ (Fig. 6).

Evans prefirió lo sencillo, los pequeños cementerios y la vida en las pequeñas ciudades, partes de una misma eternidad. En Alabama, en 1936, su sensibilidad se detuvo frente a una pared de ladrillos ocupada por dos grandes cartelones publicitarios. En uno de ellos, uno de los numerosos mitos del Far West gana una más de sus inevitables victorias. En el otro, una sociedad de color, vestida de etiqueta, celebra su "existencia". Literalmente, este anuncio dice así: "El Sur Soleado. Gran espéctaculo circense. Los grandes cómicos de J. C. Lincoln. Sólo por una noche. 25 centavos". El tiempo pasa deprisa para todos los ideales, pero un tacto vespertino por unas horas parece excesivo. Sin embargo, el cartelón ya está rajado, y los ladrillos, aparecen, verdadera potencia atemporal, por entre las figuras deshechas de una sociedad danzante que ha hecho de su bienestar utópico una "función". Los que creyeron, tal vez pudieron pagar la entrada y asistir a la gala. Los que no creyeron - llegaron tarde, en realidad componen idéntica multitud en el mediodia

4 Lemagny, Jean-Claude y Rouillé, André, Historia de la Fotografía, 286 págs. Barcelona, Ediciones Martínez Roca, 1988, capítulo VII, La sociedad americana, por Christopher Philips, pág. 160. 




Fig. 6 El poderoso espectáculo de los cómicos. Alabama 1936. Walker Evans.

de la mañana siguiente: el ideal sólo puede alcanzarse bajo los focos de un circo. Los ladrillos quedan imperturbables. Son el muro de la historia, aquél que nunca expuso ademanes amiguistas con ideal alguno.

\section{STALIN, ÚNICA FILOSOFIA PERMITIDA}

El comunismo de Estado se sintió fascinado por el hecho fotográfico: los ímprobos esfuerzos que suponía construir un ideal, desde un partido de masas a un Ejército popular, y desde la colectivización agraria a la electrificación nacional, tenian en la fotografía un aliado inestimable. Todo el país soviético conocia asi con certeza, con «exactitud", las dimensiones de una revolución maximalista en marcha.

1917 supuso un cambio importante en las conductas artísticas. Ya no se trataba del arte por el arte de Cousin, vigente sólo para los salones 
peterburgueses, ni tan siquiera de un utilitarismo economicista a lo Stuart Mill y trasplantado a la "imaginación" artística, sino que se laboraba en pos de un cientifismo del arte, el arte productivo. Se trataba de ensalzar una nueva cultura, aquella que emergía de una sociedad hasta entonces esclavizada, con las dinámicas presentes del progreso y el bienestar a las que ella misma se había hecho merecedora por su audacia revolucionaria. Surgia de esta manera una síntesis estética de lo proletario convertido en arte y ciencia, una misma cultura, Proletkult.

El movimiento originado en torno a los ímpetus poético-propagandísticos de Vladimir Vladimirovic Maiakovski (1893-1930), bolchevique de primera hora, y junto con Viktor Khlebnikov (1883-1922), que influyó grandemente en su estilo, los pilares del movimiento futurista ruso, germinó en la revista Lef (Levyi Front Iskoustva o Frente de Izquierda del Arte), donde se dieron cita, entre 1923 a 1925, los constructivistas y formalistas junto con los seguidores de Maiakovski. Uno de los miembros de Lef será Alexandr Rodchenko (1891-1956), el más grande de los fotógrafos soviéticos y uno de los hitos de la fotografía universal. Junto a él, nombres como Mihail Napelbaum, excelente retratista; Max Alpert, fotoreportero de los fastos colosalistas del sovietismo; Ivan Sagin, sensible intérprete de los festivales del sistema o Piotr Ocup, cronista gráfico del conflicto ruso-japonés de 1905 y luego testigo de todos los sucesos revolucionarios, formalizaron la coral del comunismo fotográfico convertida en palabra de Estado y en prueba artística sin más.

La URSS era un ideal complejo pero a la vez extremadamente sencillo. Una sociedad trabajadora, con un sustento digno y unos niveles "activos" de competitividad estratégica (en lo económico, en lo militar, en lo político) era todo lo que se pedía a la sociedad comunista. La máquina comenzó a trabajar a toda presión. Grigori Sudakov, en su notable introducción sobre la fotografía soviética, hace ver que ya el 27 de agosto de 1919, y por medio de un decreto gubernativo visado por Lenin, se "transfiere toda la industria y el comercio fotográfico bajo la autoridad del Comisariado del Pueblo pertinente" ${ }^{5}$. Dirigía éste Anatolij Lunacarskij, hombre de vasta cultura que sabía de las posibilidades del medio y que coordinó a lo Matthew Brady una nueva "campaña militar" en un país ciertamente en guerra (ideológica, cultural, geopolítica) con el mundo.

Rodchenko consideraba al objetivo de la cámara fotográfica como "la pupila del hombre cultural en una sociedad socialista" ${ }^{6}$. Sus escor-

5 Sudakov, Grigorij, Pioneri della fotografia sovietica 1917-1940, 252 pág. Milano, Idea Books Edizioni, 1983, pág. 10.

6 Ibidem, pág. 18. 
zos, sus visiones cenitales de las acciones humanas, situaron a su propio autor "por encima" de la revolución que plasmaba con sus imágenes. En uno de sus favoritos contrapicados, Rodchenko compuso en 1929 un haz de postes para lineas radioeléctricas (Fig. 7), que se elevaba en sentido triangular hacia el cielo. Estaba llevando a la realidad las tesis de Lenin en 1921, cuando dijo aquello de que "el comunismo es el poder de los soviets más la electricidad". Sensación de fuerza, de rusticidad indomable, un constructivismo a lo Tatlin que perseguia alcanzar el infinito, pero con la efectividad de la que careció el maximalismo del monumento concebido en honor de la III Internacional, asfixiante zigurat de 400 metros de altura en hierro y vidrio que Vladimir Tatlin diseñara en 1919 para quedar convertido en maqueta (lo que hablaba a favor del sentido pragmático del ideal soviético).

La guerra contra los Blancos y el desplome de las ya de por sí débiles estructuras agroindustriales, provocó en 1920 una gran hambruna, que el ideal de Oriente trató de aliviar recurriendo al de Occidente. Una comisión norteamericana (senador Jhonson) viajó a Moscú y decidió enviar ayuda, que se concretaría en sucesivos fletes de alimentos por valor de 30 millones de dólares y un principio de colaboración técnica que fue efímero. De aquellos ideales entre dos utopías, queda la imagen lograda por Boris Ignatovic (1899-1976), en la que un niño-obrero saluda alborozado al futuro desde lo alto de su tractor Fordson (literalmente, "el hijo de Ford") (Fig. 8). Una progenie con complicaciones genéticas insolubles.

Rota esta comunicación, se buscaron encuentros en el propio interior. Arkadij Sajchet (1898-1959) recogería en sus fotografías el inicio de los denodados trabajos para abrir cauce al Turtasib (contracción del ferrocarril entre Turkestán y Siberia, de 1.140 kilómetros, que se complementaría entre 1930 y 1932, dentro del primer plan quinquenal). Ambiente de epopeya, jubilosa celebración por alcanzar el «fin del mundo". El ideal soviético cumplía con el ritual de descubrir su infinitud igual que lo hiciera el norteamericano, cuando dos convoyes de esfuerzos mecánicos, laborales y financieros, procedentes del Este y el Oeste, confluyeron en Promontory Point (Utah) el 10 de mayo de 1869. En la URSS ya estalinista no pudo darse este «abrazo entre locomotoras", puesto que el afán se dirigía en una única dirección y en el espacio opuesto sólo había silencio (geográfico, humano, histórico). Esto no desmerece en nada aquellos logros conseguidos por un pueblo que tenia derecho a un ideal.

En 1921 se habian sublevado los marinos de Krondstadt, para protestar contra la burocracia creciente, la miseria imparable y la degradación del ideal revolucionario. Lenin, ante la revuelta de los revoluciona- 




Fig. 7 Antena de radio. 1929. Alexandr Rodchenko. 


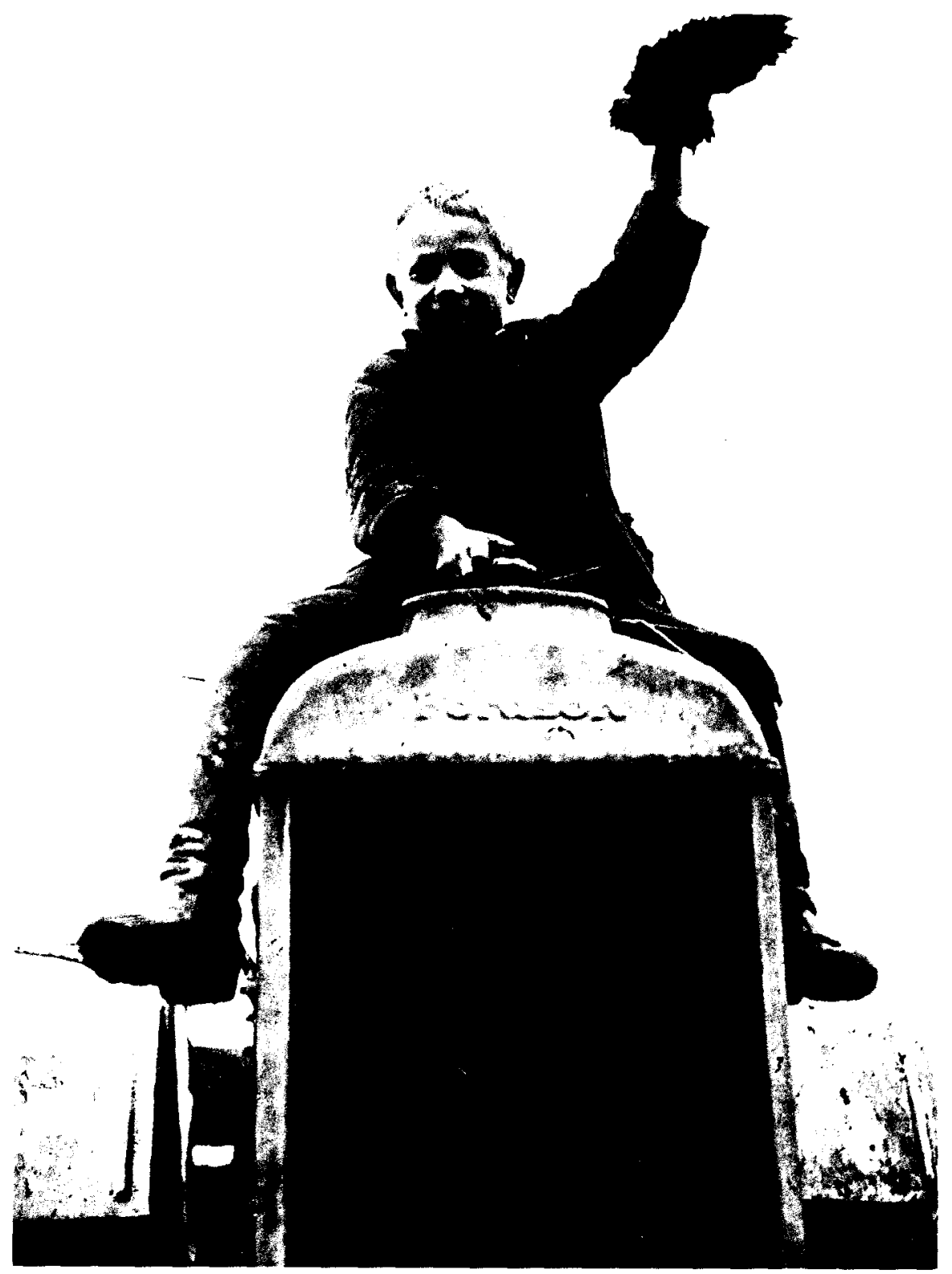

Fig. 8 El primer tractor. 1927. Boris Ignatovic. 
rios, aquella marinería que había demolido el régimen zarista, quedó conmovido. Ahora le tocaba a él actuar como "sistema" y aplastar a los insurgentes. De la angustia moral leninista brotó la NEP (Novaya Ekonomischekaya Politika, o Nueva Política Económica), un incipiente retorno a un precapitalismo "mejorado" que obtuvo rápidos y excelentes resultados y contuvo la espiral negativa del sovietismo. Pero Lenin murió en 1924, y la NEP fue liquidada en 1929 por lossiv Vissianovich Dzughasvili, "Stalin" ("Hombre de Acero"), el apodo que el antiguo seminarista de Tbilisi adoptó en 1913 al firmar un artículo sobre «El marxismo y el problema de los nacionalismos". Lenin era hombre implacable, pero su cultura le llevó a comprender el matiz. Stalin nunca supo lo que era ese término. Permitió la idolatria del leninismo como excusa de sus propósitos de sacralización de su propia persona. No perdonó a quienes, como Bujarin - Trotski, advertian insistentemente sobre el cáncer burócrata y la corrupción del ideal. Combatió con saña la revolución permanente del trostkismo e impuso los principios del socialismo en un solo país, la revolución maniatada. El ideal dejó de pensar como "ejemplo del mundo" y se limitó a amurallarse desde el terror como un imperio cualquiera. Fue el final del comunismo.

La fotografía recibió también el impacto, y se fragmentó. Un grupo, liderado por Rodchenko y al que también perteneció Ignatovic, creó en 1928 la revista Oktiabr (Octubre), que trataba de luchar contra la "deformación de la realidad". A ellos se opuso la ROPF (Russkoie Obchestvo Proletarskikh Fotografov, o Asociación Rusa de Fotógrafos Proletarios), donde militaban Alpert y Sajchet, que acusaban a los rodchenkistas de "deslizarse mecánica y superficialmente" sobre la dimensión revolucionaria ${ }^{7}$. La acusación era seria, puesto que todo lo que suponía apartarse del dogma conllevaba la catalogación de "revisionista» o de "pequeño burgués", definiciones con final sombrío. Como no podía suceder de otra manera, la pugna concluyó en 1932 contra una "autocrítica" del grupo Octubre, que reconoció públicamente sus "pecados". El 23 abril de 1932, el Comité Central aprobaba un decreto por el que se disolvían prácticamente todas las asociaciones literarias y artísticas, y en particular las "unidades" de reporteros fotográficos, un ejército sin duda temible. El estalinismo había llegado a la fotografía y el ideal sufrió un efecto de velado intensísimo.

En 1931, Sajchet fotografió a un joven miembro de la Komsomol (Juventudes Comunistas) (Fig. 9), manipulando una enorme rueda fabril. Parece haber un cierto espíritu del Tiempos modernos de Charlie Cha-

\footnotetext{
7 Lemagny y Rouille, op. cit., págs. 132-134.
} 


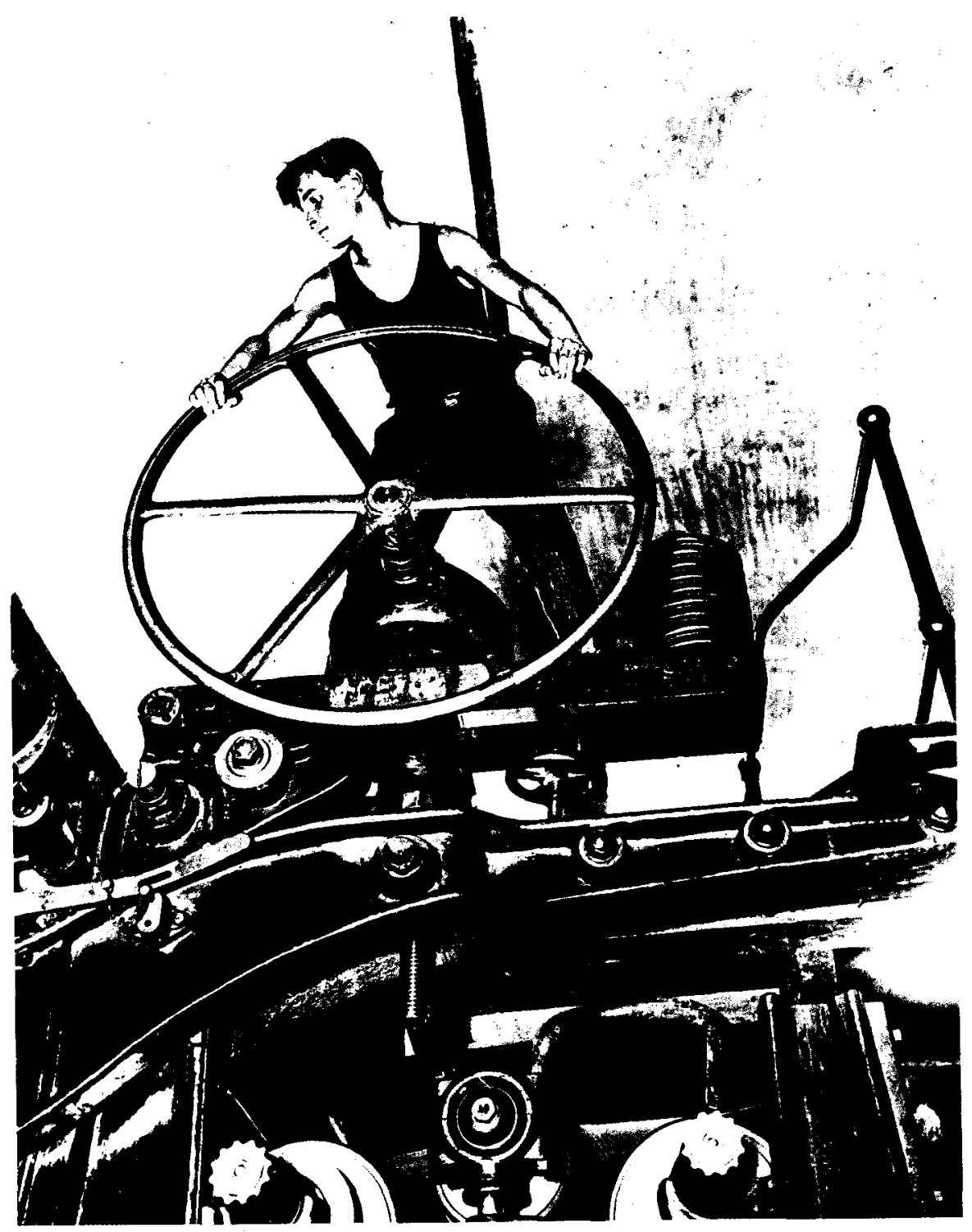

Fig. 9 Un komsomol al mando. 1931 Arkadij Sajchet. 
plin, pero nada más lejos de la verdad. El asunto no posee ninguna connotación humorística: está en movimiento una gran fábrica del miedo y, suprema felonía, una juventud inocente acciona los mandos de una trituradora de adultos que cubrirá de oprobio al ideal en las grandes purgas de 1934-37. La conclusión podría ser ésta: con una sola filosofía es imposible construir, físicamente, un ideal.

\section{DE UN ARTE DE REPOBLACIÓN A OTRO DE DESFORESTACIÓN}

Stalin había sido el "padrecito de los pueblos" pero también el de los cementerios. Su desaparición en 1953 fue un alivio universal, y el ideal soviético fue el primero en reconocerlo, aunque el hecho sólo sucedió en 1956, cuando Nikita Kruschof, ante el XX Congreso, habló de "los odiosos crimenes de Stalin". La sorpresa para los fieles al sistema se atemperó bastante con la hecatombe magiar que cumplieron eficazmente los carros de Koniev en octubre de ese mismo año, y el ideal, rechinando los dientes, siguió adelante: más fotografías de la tractorización, más éxitos de la culturización gimnástica de un ideal que comenzaba a triunfar en las Olimpiadas, más garantías de dominar el futuro.

Los grandes del sovietismo fotográfico estaban ya retirados o muertos, pero sobre la chirriante andadura del maquinismo neoestalinista gravitaba una mirada penetrante, la de aquella entrañable madre que retratara Rodchenko en 1924 (Fig. 10). Ella era el tiempo, la visualización de las pequeñeces humanas, el filtro que separaba instantáneamente la verdad de la mentira. $Y$ que no comprendía la aberración de unas conductas miserables en ambos ideales, porque la matrona de Rodchenko era la progenitora de cualquier ideal.

El arte norteamericano es un arte de repoblación. $Y$ más aún, de "comunicación». Ya en 1908 el mismo Stieglitz inauguraba en un local sito en el número 291 de la Quinta Avenida un lugar de peregrinación (de interacciones) artísticas. Alli convivirian estéticamente Matisse, Georgia O'Keefe, Picasso, Max Weber o Arthur Dove, con una pléyade de jóvenes valores fotográficos del país, como Paul Strand (1890-1976) o Charles Sheeler (1883-1965). John Pultz, en su análisis sobre la fotografía norteamericana entre 1918 y 1945, dice que «los experimentos de ese puñado de fotógrafos, justo antes y durante la Primera Guerra Mundial, cristalizaron posteriormente en el estilo moderno que prevaleció en los años veinte, cuando los profesionales crearon unas imágenes técnica, 


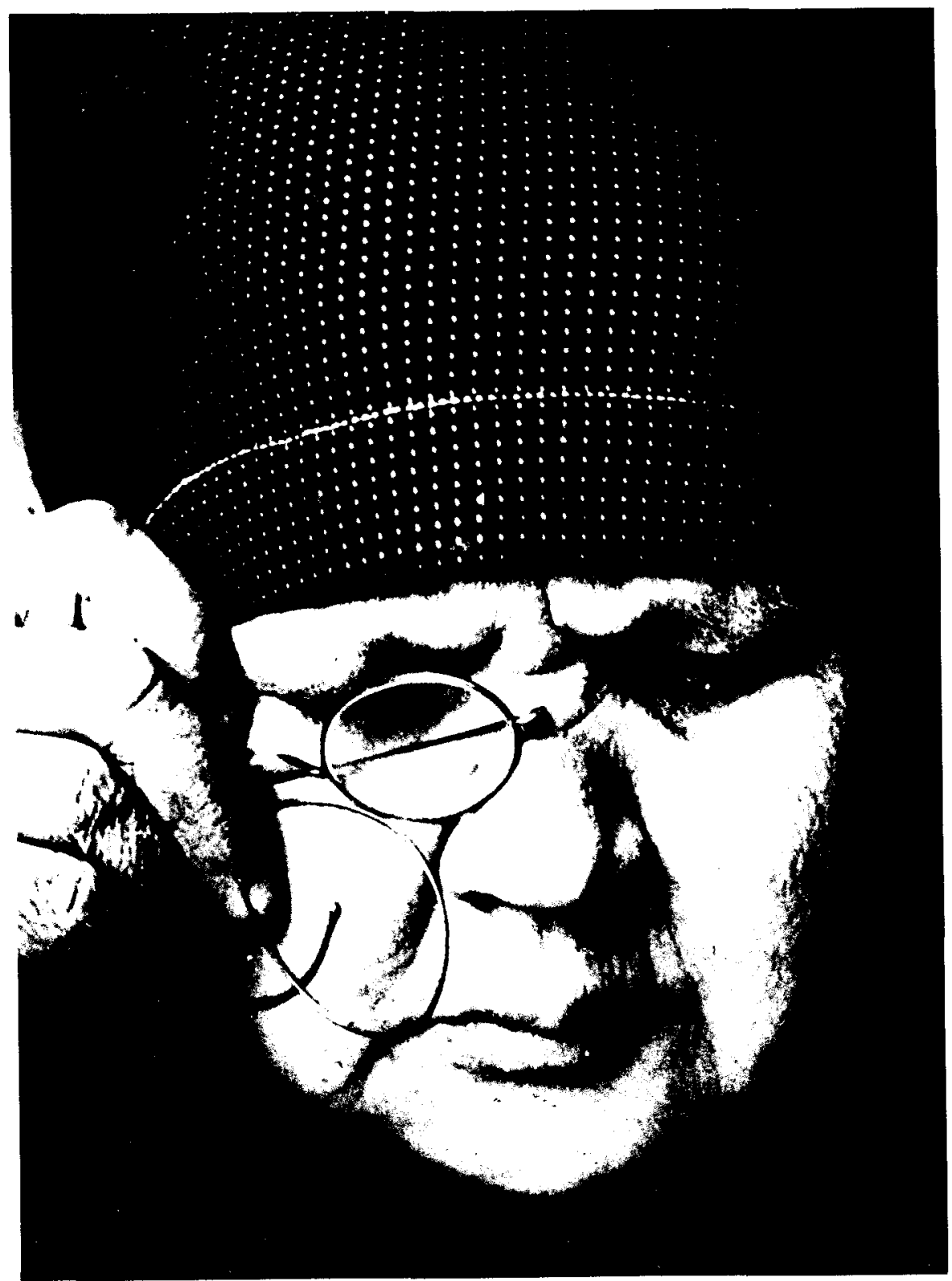

Fig. 10 Retrato de una madre. 1924. Alexandr Rodchenko. 
formal e iconográficamente al dia" ${ }^{8}$. De acuerdo, pero es que no solamente eso, sino que los Estados Unidos recibirian el beneficio de las nuevas tesis del arte concebido por los diseñadores de la Bauhaus, quienes, ante el triunfo del nazismo en 1933 (es decir, de la anti-cultura) emigraron mayoritariamente hacia el único ideal posible.

De esta forma, el "torrente continuo" bauhausiano aportaría al acervo fotográfico estadounidense nombres como Lazlo Moholy Nagy, profesor en la Bauhaus de Gropius, que fundaría en Chicago, en 1937, la New Bauhaus, convertida al año siguiente en Scholl of Design, o Andreas Feininger, que realizaría espléndidas páginas para la revista Life.

Mientras Norteamérica recibía lo mejor del arte europeo - sólo en arquitectura llegaban Mies van der Rohe, Marcel Breuer y el mismo Walter Gropius-, la URSS se vaciaba de talentos o de ilusiones. Vasily Kandisky y Antoine Pevsner (que se nacionalizaria trancés, de ahi la forma de su nombre), emigrarian entre 1921 y 1923. En 1934, el Primer Congreso de la Unión de escritores soviéticos definió la necesidad del "realismo socialista", suprimiendo radicalmente todo concepto "plural", esto es, "inútil» del arte. Nacía así la Unión de los Artistas de la URSS, simple funcionariado de quienes estaban obligados a copiar al dictado el arte oficial si es que querían seguir escribiendo "algo". Todo esto expone las diferencias entre un arte de repoblación (abierto al mundo) y un sentido de desforestación del arte, esto es, de aniquilamiento de todas las formas artísticas que no sean las productivas. La URSS se convirtió en un monumental y letal bosque de eucaliptos depredadores del arte.

\section{LAS AVENTURAS EXTERIORES: MARX Y MONROE EN EL COSMOS}

Norteamérica habia dado un segundo gran presidente en el siglo. Después del místico y honrado Wilson, que se habia retirado en 1918 afectado de una hemiplejia que le hacia vacilar entre la inconsciencia y la abulia, Roosevelt se tuvo que enfrentar al inconsciente legado económico de sus antecesores y a la perturbadora hostilidad mundial de los

\& Pultz, John. En Catálogo de Fotografía Americana del Siglo xx, fondos dependientes del Center for Creative Photography, University of Arizona (Tucson). Edición por el Patronato de "La Caixa». Barcelona 1991, 215 págs. El análisis de PULTz, Fotografía americana 1918-1945 (pág. 14), es el primero de tres estudios sobre el fenómeno fotográfico en los EEUU, los otros dos son los concernientes a los períodos 1945-1965 y 1965-1990, estudiados respectivamente por Stuart Alexander y Sheryl Conkelton. 
totalitarismos. Hacer frente a semejantes retos desde una silla de ruedas era un asombroso y emotivo ideal. Obviamente, cayó exhausto una mañana de abril de 1945. El país se declaró "huérfano", pero hubiesen faltado los estadounidenses a su propio ideario instrumentalista si no hubiesen encontrado otros «instrumentos» para convencerse de la bondad de su ideal. Truman y Eisenhower cumplieron discretamente sus funciones, como fueron las de acabar con la guerra que el anterior mandatario les había dejado como codicilio testamentario. Después llegó Kennedy, e impuso un ideal byroniano dentro del férreo pragmatismo existente, y naturalmente le mataron. Norteamérica podía ser inocente pero no queria ideales "fuera de época".

Pese a ello, la fotografía en el ideal occidental mostró un vigor y una ecuanimidad de la que carecieron sus líderes gubernamentales. Su capacidad de producción de la verdad fue ciertamente magnífica: desde el naturalismo perfeccionista de Ansel Adams, y el espiritismo inquietante de Henry Callahan o Minor White, al estudio áspero, estremecedor, del hombre suburbano por Roy de Carava, y el realismo nocturno, esa "vida en un relámpago", que Arthur Fellig, "Weegee", retrató como nadie, ya fuese en un ajuste de cuentas entre mafiosos o en la llegada a una première de damas enjoyadas, cubiertas obscenamente de pieles muertas, las anti-madres de Rodchenko que Maiakovski no hubiera dudado en fusilar.

Norteamérica, como idea, se criticaba duramente a si misma. Y esto permitía sobrellevar manifiestas incapacidades de su política, al mantener intacta su credibilidad. La URSS de Kruschof no lo creyó necesario, y en sustitución de la crítica del sistema por el arte envió a los espacios negros tres "objetos" que se adelantaron, consecutivamente, a sucesivos intentos norteamericanos por superarlos. El primero fue el «Sputnik» ("compañero de viaje"), lanzado el 4 de octubre de 1957; después llegó el «Sputnik 2," el 3 de noviembre, con un compartimento que contenia a "Laika", el primer ser viviente en el espacio, y finalmente la nave "Vostok" ("Oriente»), ponía en órbita el 12 de abril de 1961 al primer ser humano satelizado de la tierra, Yuri $A$. Gagarin. Fue el único que pudo volver de los tres lanzamientos, lo que dice mucho en favor del nivel cultural alcanzado por el neoestalinismo cósmico.

Marx en el espacio era algo insoportable para los norteamericanos. Se produjo una segunda "gran depresión", y los psiquiatras del pais vieron saturadas sus consultas por inquilinos provenientes de todas las urbanizaciones, incluida la Casa Blanca. Sentirse vigilados desde lo más alto por las tesis marxistas-leninistas obturó la inteligencia estadounidense, nunca especialmente bien preparada para estos debates existencia- 
les. El 5 de mayo de 1961, a la desesperada, y corriendo grandes riesgos, Alan Shepard fue catapultado al espacio para un a flea jump ("salto de pulga») de quince minutos. Desde el suelo, Robert Kelley fotografió a las mujeres del equipo de astronautas norteamericanos señalando eufóricamente la ascensión a los cielos de uno de ellos (Fig. 11). Dios parecía ser de nuevo misericordioso con los Estados Unidos.

La pesadilla terminó el 21 de julio de 1969, cuando Neil Armstrong retrató a su compañero de vuelo, Edwin Aldrin, sobre un desolado paraje lunar: bóveda negra circundante; luz absolutista y sombras no menos totalitarias; imagen de robot sonriendo entusiásticamente tras el filtro opaco de la escafandra. Se estaba muy lejos de las serenas panorámicas de Carleton E. Watkins o Timothy O'Sullivan sobre los espacios museísticos del Oeste inexplorado. Pero persistía el mismo afán de aventura, el mismo "elán» de aquellos pioneros. El uniforme tecno-científico se consideró accesorio. $Y$ aunque la plástica selenita fue efímera, había bastado para demostrar que Monroe era ampliable a las trayectorias celestes. La Luna era para los norteamericanos. Los que pareció muy justo.



Fig. 11 Las mujeres de los astronautas contemplan el Lanzamiento. Cabo Cañaveral. (Florida) 1961. Robert Kelley. 


\section{EL EFECTO DE RETORNO Y LA OBRA INACABADA}

Antes de la gran explosión soviética de 1991, siguiendo ese efecto de estallido silmultáneo que sintetizara Erich Khaler como linea directriz en los procesos revolucionarios de la historia ("lo que les convierte en momentos cruciales es el estallido simultáneo de unas fuerzas latentes que se habían ido formando desde mucho tiempo atrás y su conjunción..."), válido para todo tipo de suceso cataclismico en geopolítica ${ }^{9}$, la URSS habia generado en su seno su propia revolución hacia la verdad. $Y$ nuevamente el arte se había erigido en vanguardia de ese movimiento, porque el arte es la revolución indesmayada, aquella que no se atiene a otra premisa que la de criticarse (renovarse) a sí misma, lo que la convierte en "inmortal», al mismo tiempo que se desprende de la soberbia de creerlo.

El totemismo soviético había originado un gran ballet de sumos sacerdotes en Moscú. A la deposición de Kruschof en 1964 y la muerte de su sucesor, Brejnev, en 1982, se sucedieron los tránsitos de Andrópov y Chernenko. La espiral se detuvo en Gorbachov, que intentó hacer competitivo al sistema y provocó su desintegración. Para entonces, el sentido oficialista de la vida soviética había sido repudiado por el pueblo y, desde luego, por el arte. En la fotografía, Boris Mikhajlov (nacido en 1938) nos acercaba al ambiente de una sociedad tristemente festiva en playas, bailes y gimnasios; Lyala Kuznetsova (n. 1946), estudiaba las realidades tartáricas 0 el mundo fascinante de la mujer, desde un velatorio a una función circense; Vladimir Siomin (n. 1938) profundizaba en el terreno laboral y vacacional del pueblo pero bajo el prisma de la sencillez, de la objetividad; finalmente, una vigorosa fotografía báltica y especialmente lituana (Algimantas Kunchius, Aleksandras Matsiyauskas o Egons Spuris), componía un vibrante testimonio de la fertilidad estética de un pueblo que jamás se resignó a ser silenciado.

La fotografía "soviética" estaba viva y de qué forma. Se habia producido un gigantesco efecto de retorno en el que todavía hoy, afortunadamente, permanece, y del que estoy seguro ya no se apartará: el encuentro con la sinceridad, con la intuición, con el talento expresivo. Se volvía a aprender cómo componer, cómo dominar las perspectivas, el hacer creibles los gestos, el consignar a las presencias su imprescindible trascendencia. Este retorno a los mandatos de Rodchenko era y es algo

9 KHaler, Erich, El significado de la Historia, 211 págs. Barcelona. Círculo de Lectores, 1988, pág. 190. 
hermoso, impresionante por su vigor y por las dificultades con que tenia que debatirse. El miedo, la beatería hacia formas inmovilistas, el concepto autoritario del arte, habían "producido" finalmente una liberación de la cultura tanto tiempo secuestrada. Se imponían los viejos modos, aquellos que nunca caducan: la audacia, la íranqueza, la honradez, principios fundamentales en la conducta del hombre y en la sintesis artística.

El sistema necesitaba un final, y se lo puso en su momento Eduard Gladkov (n. 1939), en un reportaje (Fig. 12) que realizó en 1982 en el pueblito de Tchachnicy, a pocos kilómetros de Moscú: la dureza del mundo rural, el fluir de las sombras de una vida interior en "blanco y negro", el esquematismo absorbente de una existencia bajo mínimos. De aquella serie es una obra, sin título, que muestra las botas campesinas puestas a secar luego de una áspera jornada en la tierra. Como muñones icónicos, estiran ante el sol moscovita sus cuellos cuarteados, sus mandíbulas cansadas. No son los rostros de los grandes profetas soviéticos, sino tan sólo sus "enseñas", sus mandamientos: trabajar hasta la extenuación,



Fig. 12 Sin titulo. Tchachnicy (Moscú) 1982. Eduard Gladkov. 
hasta que la felicidad del socialismo esté con vosotros. Ahora se orean bajo la luz de la tarde postsoviética, y en la mañana inmediata el pueblo ruso las volverá a calzar para seguir trabajando en el surco de la historia. Como antes, como siempre. Pero sin miedo.

lan Jeffrey, en la introducción al notable libro sobre la fotografía rusa que seleccionó el matrimonio checo Mrázkova-Remes, califica al conjunto de lo expuesto como "algo que gira cada vez más a lo muy afirmativo, misterioso y analítico" ${ }^{10}$. Nada sorprendente si consideramos que se trata de exponer las dimensiones de una comunidad de conductas, de grandes inercias históricas y de constituciones culturales. $Y$ eso, ciertamente, exige fuertes dosis tanto de voluntad testificativa como de mantenimiento de lo incógnito.

Los Estados Unidos saben el precio de la verdad, pero regularmente olvidan esta premisa cuando se embarcan en aventuras exteriores. Las canteras coreana y vietnamita se encargaron de recordar la aridez de sus perfiles. En Corea hubo «un poco» de gloria, posiblemente porque el ideal combatía bajo el mandato de Naciones Unidas y esto tranquilizaba el conocimiento de las matanzas, pero en Vietnam el honor estadounidense actuaba en solitario y en numerosas ocasiones fue dado por desaparecido.

Sin embargo, la valía de los corresponsales de guerra y el coraje de los ejecutivos de televisión, que autorizaron la transmisión en diferido del horror, elevó tanto el honor del pais como hizo ver la aberración de por quiénes y cómo se combatía. Una imagen (Fig. 13), la lograda por Edward T. Adams (n. en 1934), durante las luchas callejeras en Saigón en 1968, y en la que se encuadraba el momento mismo de la ejecución de un presunto vietcong por el brigadier survietnamita Nguyen Ngoc Loan, dejó estupefacta y horrizada a Norteamérica. La fotografía de Adams sería Premio Pulitzer al año siguiente, pero para entonces ya había renunciado a la reelección el presidente Johnson, no por "una» fotografía sino por una saturación de imágenes similares.

Marianne Fulton, en su estudio sobre el periodismo norteamericano y sobre el conflicto del Vietnam, dice que ula compleja y contradictoria naturaleza de la presencia de los americanos en el Sureste de Asia iba

10 Mrazkova, Daniela y Remes, Vladimir, Another Russia, 176 págs. Introducción de lan Jeffrey. Thames and Hudson, London 1986, pág. 16. Mrazkova y Remes, nacidos ambos en Praga (en 1942 y 1932, respectivamente), han desarrollado una amplia labor documentalista de la fotografía eslava. Ambos han trabajado en la televisión estatal checa y realizado varias exposiciones en Europa sobre el estudio de sus inquietudes. 




Fig. 13 Vietcong ejecutado. Saigón 1968. Edward T. Adams.

tomando forma según avanzaba el trabajo diario del periodismo" ". Adams y otros como él (Larry Burrows o John Philips Griffiths, británicos los dos), hicieron ver al pueblo norteamericano la gravedad de las marismas en las que estaba enfangado el ideal. El síndrome de Vietnam duró décadas, y se dice que sólo sanó en una fulgurante guerra que hubo contra un tirano en Irak, en el invierno de 1991. Sólo sabemos que en esta otra ocasión los periodistas fueron agrupados en "columnas informativas", que obedecieron las órdenes de filmar, fotografiar y escribir que recibian. Algunos lo hicieron con doble sentido, pero este prurito anecdótico no molestó en absoluto la totalidad de una gran victoria.

Este ideal necesita también su final, que en este caso es únicamente un recomienzo. Lewis Baltz (n. en 1945), enfocó su cámara hacia una

"Fulton, Marianne, Eyes of Time. Photojournalism in America, 326 págs. New York, Internationa! Museum of Photography at George Eastman House, 1988, pág. 208. 


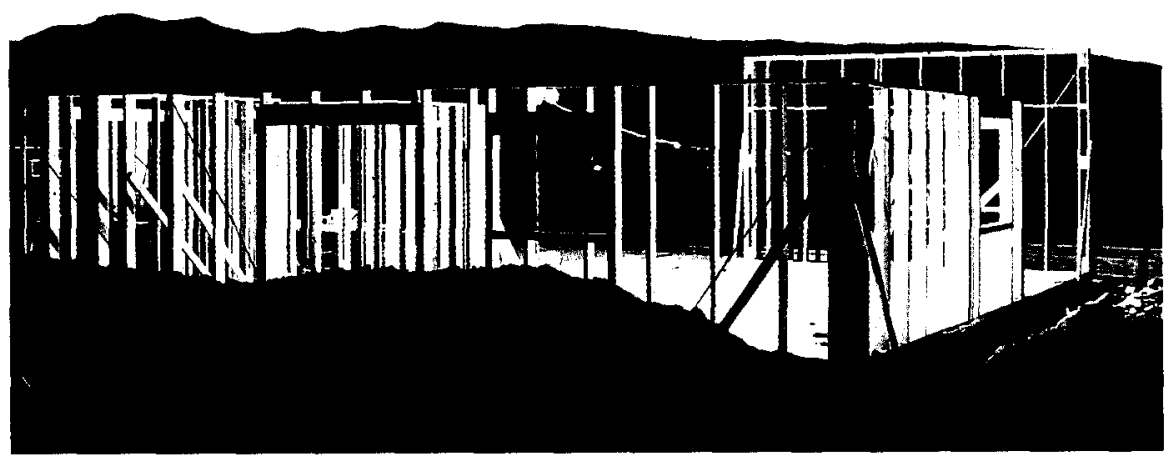

Fig. 14 Construcción nocturna. Reno 1977. Lewis Baitz

aislada construcción en Reno (Nevada) (Fig. 14), en el declinar de un día majestuoso, bajo la negritud de unas montañas que se recortan sobre un cielo que, en poco tiempo, también se transformará en montaña. Es una pequeña edificación, confeccionada con el formalismo provisional de las viviendas norteamericanas, donde la madera es elemento primordial y las estructuras son livianas por naturaleza, porque todo es mudable y todo es circunstancial (el estadounidense medio cambia con frecuencia de ocupación y de lugar de trabajo).

La casa entre dos luces de Reno está apenas apuntada como edificio en sí. Pero posee todos los imperativos del mismo, excepto el techo que, tal vez, se concluya mañana. Lo prefabricado impone secuencias vertiginosas, y no es raro que una casa se termine en seis $u$ ocho jornadas. Naturalmente, será una casa "echa por fuera", pues de la decoración interior, de su personalidad, ya se encargarán sus habitantes, y eso les llevará años. Pero como ideal de Norteamérica es perfecto: el sentido de la aventura (en medio del campo abierto); el carácter de interinidad (la casa no es para siempre, como tampoco lo es la vida); el concepto de lo pragmático (la vivienda no es la ley, e incluso ésta puede y debe ser cambiada). Por eso está incompleta, porque es evolutiva y, sin embargo, no es eterna, de la misma manera que tampoco es religión. 
¿Es éste el ideal verdadero? ¿Aquél que nunca se termina? Personalmente pienso que sí, pero esto es, claro está, un fundamento filosófico, una estética determinada, basada en una cierta experiencia y, como el ideal que nos ocupa, paralelamente inacabada.

\section{BIBLIOGRAFIA}

Fulton, Marianne. Eyes of Time. Photojournalism in America, 326 págs. New York, International Museum of Photography at George Eastman House, 1988.

JAMES, Willian. El significado de la verdad, 196 págs. Traducción del inglés y prólogo de Luis Rodríguez Aranda. Buenos Aires, Editorial Aguilar Argentina, 1974.

KASPI, André. Les Américains. Les Etats Unis de 1607 à nos jours, 697 págs. París, Editions du Seuil, 1986.

KHALER, Erich. El significado de la historia, 211 págs. Barcelona, Círculo de Lectores, 1988.

LemagnY, Jean-Claude y Rouillé, André. Historia de la Fotografía, 286 págs. Barcelona, Ediciones Martínez Roca, 1988.

Martinelli, Franco. Historia de los Estados Unidos, 2 volúmenes. Barcelona, Editorial De Vecchi, 1973.

Mrazkova, Daniela y Remes, Vladimir. Another Russia, 176 págs. Barcelona, Ediciones Martínez Roca, 1988.

- Catálogo de Fotografia Americana del Siglo xx, 215 págs. Fondos dependientes del Center for Creative Photography, University of Arizona (Tucson). Capítulo 1. ${ }^{\circ}$, Fotografía americana 1918-1945, por PULTZ, John. Barcelona, Edición por el Patronato de La Caixa, 1991.

Sudakov, Grigorij. Pioneri della fotografia sovietica 1917-1940, 252 págs. Milano, Idea Books Edizioni, 1983. 